\title{
Erratum to: The past is prologue: Moving on from Culture's Consequences
}

\author{
Timothy M. Devinney ${ }^{1}$ and \\ Jan Hohberger ${ }^{2}$
}

\footnotetext{
${ }^{1}$ Leeds University Business School, University of Leeds, Leeds, UK; ${ }^{2}$ Faculty of Business, University of Technology, Sydney, Australia
}

\section{Correspondence:}

TM Devinney, Leeds University Business School, University of Leeds, Leeds, UK e-mail: Timothy.Devinney@gmail.com
Journal of International Business Studies (2017) 48, 534. doi: | 0. I057/s4 | 267-0| 7-0065-0

Correction to: Journal of International Business Studies (2016). doi: $10.1057 / \mathrm{s} 41267-016-0034-\mathrm{z}$

This paper has been corrected owing to a typographical error pertaining to a specific reference in-text. No other changes to the article have been made.

We apologise for any inconvenience caused to our readers.

Corrections made were:

In the Introduction section, the citation Kirkman, Chen, Farh, Chen, \& Lowe (2017) should be Kirkman, Lowe, \& Gibson (2017).

In the references section, the publication year in Kirkman, B. L., Chen, G., Farh, J.-L., Chen, Z. X. \& Lowe, K. B. 2017. Individual power distance orientation and follower reactions to transformational leaders: A cross-level, crosscultural examination. Academy of Management Journal, 52(4): 744-764 should be 2009.

The below reference has been added:

Kirkman, B. L., Lowe, K. B., \& Gibson, C. B. 2017. A retrospective on Culture's Consequences: The 35-year journey. Journal of International Business Studies, 48(1). doi: 10.1057/s41267-016-0037-9.

The online version of the original article can be found under doi:10.1057/s41267-016-0034-z. 